\title{
Carnets
}

Revue électronique d'études françaises de l'APEF

Première Série - 4 Numéro Spécial | 2012

Invasions \& Évasions

\section{Capere, Non Capi: Eugénio de Castro no contexto da "Internacional Simbolista"}

José Carlos Seabra Pereira e Maria de Jesus Cabral

\section{OpenEdition}

1 Journals

Edição electrónica

URL: http://journals.openedition.org/carnets/7816

DOI: $10.4000 /$ carnets.7816

ISSN: 1646-7698

Editora

APEF

Edição impressa

Data de publição: 1 Junho 2012

Paginação: 263-273

Refêrencia eletrónica

José Carlos Seabra Pereira e Maria de Jesus Cabral, «Capere, Non Capi: Eugénio de Castro no contexto da "Internacional Simbolista" », Carnets [Online], Première Série - 4 Numéro Spécial | 2012, posto online no dia 23 junho 2018, consultado o 19 abril 2019. URL : http://journals.openedition.org/ carnets/7816 ; DOI : 10.4000/carnets.7816

\section{(c) (i) \&}

Carnets est mis à disposition selon les termes de la licence Creative Commons - Atribution - Pas d'utilisation commerciale 4.0 International. 


\title{
CAPERE, NON CAPI \\ Eugénio de Castro no contexto da "Internacional Simbolista"
}

José Carlos Seabra Pereira e Maria de Jesus Cabral Universidade de Coimbra / CEC / CLP

\begin{abstract}
Resumo
É em invulgar interacção com a cena literária euro-americana e com inédita rede de relacionamentos na "Internacional simbolista", mas também com vigilante e tenaz esforço de exploração do seu próprio idiolecto literário - capere, non capi -, que a personalidade artístico-cultural de Eugénio de Castro e a sua obra poética se revelam umbilicalmente ligadas a uma viragem do fim-de-século que, décadas depois, ainda os cânones críticos da história literária qualificavam como "Poesia nova". Nesse período finissecular, a figura do "esteta" torna-se paradigmática; e do seu ideal é indissociável o empenhamento árduo e ousado numa estratégia de intervenção no funcionamento institucional da literatura segundo os ditames do aristocratismo e os paroxismos da originalidade. Como pro tempore ressaltou de apoios críticos e de paródias, de controvérsias e de disputas polémicas, e como vieram confirmar estudos novecentistas, Eugénio de Castro afirma-se então como o primeiro e modelar representante dessa orientação.
\end{abstract}

\section{Abstract}

Eugénio de Castro's artistic and cultural persona and his poetic work are intimately connected to the turn of the century, in an unusual interaction with the European and American literary scene and, particularly, with an unprecedented net of connections with the "International Symbolism", but also with an ever present and tenacious effort of hetero-self author peculiar use of books and suggestions for the construction of his own literary idiolect - capere, non capi. Decades later, the literary history critics were still qualifying his poetry as "New Poetry". In that fin de siècle period, the image of the "aesthete" becomes paradigmatic; and from its ideal an arduous and bold commitment is inseparable, in an intervention strategy to literature's institutional functioning according to the rules of aristocratism and the originality paroxysms. Eugénio de Castro stands out as the first and model example of that guidance, proved not only pro tempore by critical supports and parodists, controversies and polemic disputes but also by 19 th century studies.

Palavras-chave: Eugénio de Castro, "Internacional Simbolista", "novismo", interacção poética, idiolecto literário.

Keywords: Eugénio de Castro "International Symbolism", "new poetry", poetic interaction, literary idiolect. 
Eugénio de Castro manifestou precocemente e realizou persistentemente a vocação literária que, com discernimento e determinação, perscruta e prossegue os caminhos próprios da maturação e da evolução. Desde os treze anos demonstra iniciativa jornalística e destreza prosódico-versificatória - quer em breves poemas líricos destinados a umas Rítmicas que, logo após o opúsculo elegíaco que traz como título a extraordinária metáfora de Cristalizações da morte (1884), virão a metamorfosear-se em Canções de Abril (1884) e a prolongar-se em Horas Tristes (1888), quer em fragmentos de projectos poéticos mais ambiciosos: um malogrado poema transformista, uma Epopeia do Calvário, que se refundirá num Jesus de Nazaré (1885) e uma Camoniana que redundará na sequência de sonetos Per Umbram... (1887).

Aliás, essa fase adolescente e juvenil de criação poética decorre já nos meios cultivados de Lisboa para onde o filho e neto de lentes conimbricenses quisera deslocar-se para frequentar o Curso Superior de Letras... e colaborar em revistas e jornais (tornando-se mesmo redactor d'O Dia de António Enes). Trata-se de um movimento táctico de distanciação da familiaridade do ambiente coimbrão, que há-de repetir noutra fase - no âmbito de uma espécie de estratégia ciclotímica de desacomodação e de busca na capital da intermediação dos pendores de novidade e cosmopolitismo inerentes ao espírito da modernidade estética.

Ora, enquanto n'O Instituto coimbrão o poeta confirma as potencialidades de escrita lírica com versões do Intermezzo de H. Heine, em periódicos lisboetas como a llustração Portuguesa surpreende em 1887, talvez sob a influência do convívio com Fialho de Almeida, com contos de fantástico hoffmanesco («O Casamento do Mar», «Paulina»), com uma novela baudelairiana («Valentina») e com poemas em prosa de mórbida estesia (com destaque para o folhetim «Visões do haschisch» que vai em busca do "natural excessivo" com que nos Paradis Artificiels Baudelaire devolvia às coisas o seu poder emocional originário). Ironicamente, neste insuspeitado rasgar de caminhos para uma frente de inovação literária alguns vectores e dotes não estarão isentos de riscos de sobrecarga alegorizante ou de ostentação decorativa de elementos rebuscados, exóticos, bizarros; e as

\footnotetext{
${ }^{1}$ Carta de Stuart Merril a Eugénio de Castro de 4 de Dezembro de 1895, aludindo à publicação recente de Arte, revista internacional. Esta e todas as cartas citadas neste artigo encontram-se no espólio epistolar de Eugénio de Castro conservado na Biblioteca Geral da Universidade de Coimbra.
} 
próprias qualidades de lançamento narrativo que $\mathrm{V}$. Nemésio haveria de louvar na sua poesia, implicariam para esta tentações de discursividade narrativa e/ou descritiva contra a estética da sugestão simbolista (e a cominação mallarmeana: "pas de reportage").

Todos estes conseguimentos primaciais deveriam culminar na publicação de um volume de Novas Poesias que viria patrocinado por uma "Censura" prologal de João de Deus e que, através de ilustrações de Columbano, confirmaria os indícios que o requintado opúsculo Per Umbram... dera da sensibilidade do poeta à insubestimável materialidade do Livro e à potenciação da estesia pela confluência de semioses artísticas. Mas tal livro será repudiado num gesto que historicamente valerá não só como impressionante exercício de crescimento crítico da consciência artística do jovem Eugénio de Castro como também de sacrifício propiciatório de iniciação em novo rito estético-literário.

$\mathrm{Na}$ contracapa de Oaristos já os volumes juvenis são referidos como "edições esvaídas" ou "prestes a esvair-se" - forma de assinalar, com seu moderno toque de snobismo, o esgotamento de determinado tipo de literatura, doravante caduco perante o advento de novo modo da "qualidade de divergência" com matriz baudelairiana. Novo estilo, sim, mas não só; também nova fenomenologia da percepção antipositivista, explorando as virtualidades de estranhamento até às fronteiras de uma «clownerie» controlada. Antes de António Nobre, e de maneira diferente, Eugénio de Castro revelava lúcida compreensão da existência moderna da literatura como campo de bens simbólicos e como instituição sociocultural; e realizava arguta movimentação na dinâmica do campo literário e no funcionamento institucional da literatura (Pereira, 1999).

É no quadro da continuidade desta reorientação estética que se afirma como dominante da obra de Eugénio de Castro a precedência e a perenidade da beleza artística. Se a literatura portuguesa (sempre atraída pelos convencionalismos heterotélicos) contraiu preciosa dívida para com o exemplo castriano de continuado e esclarecido esforço de revitalização temático-formal, essa dívida é indissociável daquela que a cultura (literária e cívica) nacional contraiu perante a sua ética do esteticismo. E perante a constante lição do valor moral do labor artístico e a modelar poesia de busca da Beleza pelo desejo, colhe lembrar que, tendo sido Eugénio de Castro quem pioneiramente assinalou em Portugal "os assombrosos trabalhos de Nietzsche», a sua concepção e a sua prática do processo de criação literária não só antecipam a modulação da teoria intelectualista "from Poe [and Baudelaire] to Valéry" pelo fingimento poético pessoano, como correspondem - de novo: capere, non capi - ao ditame nietzscheano: "Onde há beleza? - Lá onde eu quiser com toda a minha vontade".

A feição insólita que ganha a poesia de Eugénio de Castro não reside apenas no estilo, na prosódia, na linguagem. Nem o seu carácter instigante se circunscreve à 
excentricidade de motivos, ambientes e figuras. Todavia, mesmo o legado castriano de sondagem do subliminar e do arquetípico, do mitográfico e do esotérico, é indissociável quer da profusa e fulgurante imagística, quer da versatilidade fónico-rítmica e rimática - que terão insofismável recepção criativa na literatura modernista. Apesar do pendor derradeiro do poeta para o academismo, esses dons fecundam ainda o palimpsesto de muita poesia do primeiro Sá-Carneiro e de outros modernistas.

Aliás, essa receptividade modernista a certos aspectos da baudelairiana primazia do Novo na obra de Eugénio de Castro teria ainda mais abertas razões de surgir se os escritores de Orpheu e de Presença conhecessem os rasgos a que, entre Horas e Silva, o seu autor se entrega no âmbito da referida estratégia literária de ciclotímica desinstalação. De facto, durante segunda deslocação para Lisboa em 1892-93, Eugénio de Castro não se acomoda no seu recente estatuto de «Arauto e Rei» do novo período literário. É certo que continua a compor poemas congéneres, que consolidarão tão recente e fulminante proeminência com o insuperável capital simbólico que constituirá em 1894 a publicação num só ano de três obras tão ricas como Silva, Interlúnio e Belkiss. Ao mesmo tempo, porém, empenha-se de outro modo no jornalismo cultural, numa deriva incomum de rotação de signos estéticos e de exploração de territórios de escrita e de figuração artística.

Por um lado, embora com a faceta circunstancial e a reivindicação pro domo sua, são relevantes as suas digressões no Jornal do Comércio sobre «A Poesia Moderna» e sobre a sua renovação conduzida pela literatura decadentista e simbolista - quando nesse jornal e nas Novidades pretende gravar historicamente a sua pessoal precedência na implantação em Portugal desse movimento (Castro, 1892).

Por outro lado, sendo incontestavelmente o escritor «novista» que com mais clareza programática e com mais determinação comunicacional se situa no campo literário, e também aquele que mais metodicamente cuida da difusão da sua obra no estrangeiro, Eugénio de Castro demonstra então que a componente cosmopolita de tal modernidade poética era nele irredutível a mera vaidade diletante, antes detinha pregnante função sistémica - ad intra e ad extra. Arremetendo em polémica com o ainda inevitável M. Pinheiro Chagas, no início de 1892, Eugénio de Castro reafirma, com superior ironia, o aristocratismo estético e patenteia a sua intimidade única com a vida literária europeia de epicentro parisiense - o que fica mais notório quando cuida de esclarecer melhor os pressupostos da sua poética através da demarcação relativamente a René Ghil e ao evolutivoinstrumentismo. Noutros escritos de idêntica cultura cosmopolita Eugénio de Castro vai sublinhando directrizes mentais e artísticas que fecundam a sua criação literária, em especial numa coluna de «Prosas Decorativas» nas Novidades. Aí, ao lado de textos de ambígua natureza narrativa, semificcional e semiautobiográfica (v.g. «Dois Solitários»), 
subscreve comentários ideologicamente comprometidos a factos e tendências da época: ora enaltece o ressurgimento religioso e o seu influxo na arte, ao ponderar o fenómeno do «Dandismo católico» e ao assinalar sob óptica antipositivista a morte de «Ernest Renan»; ora associa a defesa do aristocratismo estético à apologia do insólito em arte, a propósito de «Duas Estátuas» (Baudelaire e Barbey d'Aurevilly).

Mas a produção de Eugénio de Castro nesses anos vertiginosos está longe de se circunscrever a tais modalidades discursivas de agitador cultural, antes se desmultiplica em sondagens surpreendentes de novos domínios de inovação literária e promissoras tentativas de outros tipos de escrita - sempre sob o signo da «modernidade»!

Como que preparando terreno para os sucessivos poemas dramáticos que a partir de Belkiss comporá, publica no Diário Popular importante artigo «Opiniões: o Teatro Moderno», onde, após protestar contra o marasmo da arte dramática e considerar que poucos (com destaque para Ibsen e Maeterlinck) buscavam alternativas, ousava declarar ainda insuficientes as novas vias rasgadas por esses autores, pois "o teatro desta época de quintessência e nevrose deve ter por fim produzir num tempo curto uma longa série de sugestões variadas, tão variadas como as nuanças que raiam os espíritos"; e, se já assim revelava notável sensibilidade para a pragmática moderna da arte, logo se lança em indicação do novo caminho a seguir e de modo que, embora sumária, a exemplificação adiantada envolvia não menos moderna miscigenação de programas genológicos e conjugação de semioses artísticas: "sucessão de três quadros, um deles declamado, outro representado por mímica e outro dançado, o primeiro baseado num sentimento raro, o segundo reproduzido numa sugestiva cena histórica, o terceiro movendo-se sobre a fantasia dum poeta" (Castro, 1893)².

Outras vezes, Eugénio de Castro retorna ao domínio do poema em prosa, não só dando a conhecer excertos do anunciado volume Safira, mas tentando levar por diante o estímulo programático de uma «Advertência» que projectava para a prosa a requintada e musical renovação temático-formal já actuante na escrita versificada. Finalmente, enquanto consolida o rejuvenescimento de formas poéticas pré-renascentistas, ensaia inédita experiência prosódico-versificatória, em vários textos que por ironia ou por má-consciência vanguardista conglomera sob o título «Prosas». Assim surgem, a caminho de Silva, os poemas «Asilo da Mendicidade», «A Aleijadinha» e «De Toledo para o Mar» que, além de operarem no campo da estética da sugestão, julgariam realizar-se em verso livre e de facto oscilam entre o versilibrismo e uma construção heterométrica até aí inigualada em ousadia

\footnotetext{
${ }^{2}$ Veja-se, a este propósito o artigo de Maria de Jesus Cabral " «Uma grande sombra que sente e se não vê»: Belkiss nos trilhos da Literatura dramática simbolista” (Cabral, 2010 $)$.
} 
ou em mestria. Mas sobretudo assim surge o poema nesse sentido mais extraordinário (e, talvez por isso, nunca recolhido em livro): uma singular "Lapidação das Açucenas» que representa o momento em que Eugénio de Castro e a poesia finissecular portuguesa estão mais próximos da rara consubstanciação do símbolo como signo autenticamente simbolista (críptico e intuitivo, alógico e analógico) com o autêntico verso livre (unidade de som e de pensamento alheia ao princípio silábico).

Simultaneamente originário e transnacional foi sem dúvida o projecto de Eugénio de Castro à frente de Arte, revista internacional, que fundou em Coimbra com Manuel da Silva Gaio, tecendo toda uma rede de intercâmbios, nomeadamente com as consagradas L'Ermitage, La Revue Blanche e Mercure de France ${ }^{3}$. Os oito números publicados entre Outubro 1895 e Junho 1896 contam, no elenco dos seus colaboradores, um vasto leque de nomes da frente literária europeia - mormente francesa e italiana, entre os quais Rémy de Gourmont e Vittorio Pica ${ }^{4}$. Os «Boletins internacionais» percorrem um arco geográfico que vai de Espanha ao Brasil, passando por França, Itália, Alemanha, Áustria-Hungria, Bélgica, Dinamarca, Suécia, Noruega, Grécia e Turquia. Como o mostrou Jean-Marie d'Heur, a estratégia de divulgação da revista passa pelo uso de várias línguas, mormente o francês, sendo nítida “uma ambição de abordagem largamente europeia” (D’Heur, 1999: 613). Isso mesmo nos revela um simples exame do índice da revista, em que se avizinham, escritos em várias línguas, mas com predominância para o francês, textos literários - poemas sobretudo, mas também alguns contos e poemas dramáticos - e outros de teor críticoensaísta. Sem postergar a sua idiossincrasia lusa e o seu propósito de divulgar a "Jovem Literatura Portuguesa", Arte revela uma visão aberta ao exterior e a crença na capacidade da literatura em atravessar e até mesmo transcender fronteiras geográficas, linguísticas ou culturais, "no sentido da comunicação e comunhão de Portugal com o melhor das literaturas europeias" (Arte, 1895: 54). Assim se pode ler no artigo "Portugal no estrangeiro", que enumera o elenco de periódicos que permutavam com a nossa coimbrã: Bayreuther Blatter (da Baviera), Echo des Jeunes (Canada), Mercure de France, Revues des Revues, Vero (Itália) e a Zeit (Viena), entre outras. É também interessante verificar como os textos de Arte se encontram em sincronia com os escritos programáticos e poéticos que interagiam hors frontières, veiculando os novos valores da Escola idealista liderada por Mallarmé (Cabral,

\footnotetext{
${ }^{3}$ Graças nomeadamente à acção de Louis-Pilate de Brinn'Gaubast e de Philéas Lebesgue. Crítico autorizado no Mercure de France e lusófilo convicto, Philéas Lebesgue consagrou vários artigos à obra do poeta coimbrão. Foi também um dos tradutores de Belkiss e de Sagramor, que tratou de divulgar em Paris. Ver Philéas Lebesgue, 2007.

${ }^{4}$ Rita Marnoto destacou o impacto de Eugénio de Castro no futurismo italiano, com destaque para duas revistas do início do século XX: Poésie (1906), animada por Marinetti, e a Revue de l'Inde (1914) publicada em Nova Goa. Ver Marnoto, 2009.
} 
2010 ). Numa carta de Abril de 1891 ao mestre francês, Eugénio de Castro afirma-se como primeiro divulgador em Portugal da "très haute Religion Artistique dont vous êtes, avec le divin Wagner et le sublime Poe, un des plus admirables Pontifes" (Mallarmé, 1973: 228-229, nota 2). É com um vivo entusiasmo estético que Mallarmé acusa a recepção de Interlúnio (1894), que o poeta luso Ihe enviara em tradução francesa. Impressionado pela "Beleza" da poesia de Castro, o poeta francês escreve-lhe o quanto gostaria de ler na língua original, denunciando I'“absurde manie française d'ignorer les langages étrangers”. Sintomática do valor axiológico que a palavra poesia adquirira para as artes e as letras revela-se a expressão metafórica "Religião Artística", utilizada por Eugénio de Castro, também com letra maiúscula, espelhando toda a dimensão idealista, espiritual e mística que a poesia tinha na sua vida. No prefácio que Manuel da Silva Gaio, companheiro e amigo de Castro escreveu à segunda edição de Horas, assinalou, como característica essencial do seu congénere a capacidade de converter o real "em motivo de Beleza" (Castro, 1927: 75), em ruptura com a tendência realista - expressão da doutrina positivista - de subordinação ao paradigma mimético vigente na literatura contemporânea. Ao invés da arte directa "de representações e figuras" (1927: 74), que desembocava numa estagnação descritivista, é na "transposição da realidade em valores de gama ideal" (1927: 74) que reside o verdadeiro gesto artístico, "criador de Beleza" (1927: 76). Um simbolismo - sublinhado pelo autor - "no sentido de Arte de estilo como antagónica com a Arte de carácter " (1927: 76).

$\mathrm{Na}$ sua historicidade própria mas também no conjunto orgânico que formam em momento charneira de "Revolução poética" (Michaud, 1995) os textos dos simbolistas mostram quanto, para além das diferenças ou particularidades linguísticas e culturais, uma dinâmica cosmopolita acompanhou o devir da história da literatura europeia no final do século XIX. Ganha aqui todo o seu significado e legitimidade a expressão "moderna literatura cosmopolita" consagrada por Ruben Darío a este período da história literária a partir da sua obra Los raros (1896). Neste texto, o chamado príncipe das letras castelhanas afirma que descobriu a obra de Eugénio de Castro através das referências a ela feitas por Vittorio Pica ${ }^{5}$ e Rémy de Gourmont e esclarece que a leitura dos versos do poeta coimbrão "encontro abiertas de par em par la puertas de /su/ espiritu /.../. Desde el primer momento reconoci su iniciacion en el nuevo sacerdocio estético" (Darío, 1942: 208-209) ${ }^{6}$.

Uma trajectória ascendente caracteriza os percursos de Eugénio de Castro na esfera da literatura europeia, desde a sua juventude simbolista à sua distinção como doutor honoris

\footnotetext{
${ }^{5}$ Que traduzira Belkiss para italiano (Castro, 1896), saindo esta versão a lume dois anos apenas após a sua versão original portuguesa. A obra é precedida de um ensaio crítico que terá um largo impacto em Ruben Darío.

${ }^{6}$ Não será despiciendo lembrar que o poeta nicaraguense dedica o seu Reino Interior a Eugénio de Castro.
} 
causa em várias universidades (Salamanca, Lião, Estrasburgo) e à sua eleição e recepção na Academia Real da Língua e Literatura Francesas da Bélgica, em Fevereiro de 1935 por Albert Mockel ${ }^{7}$.

As traduções das suas primeiras obras em francês, em italiano e em espanhol, quase em simultâneo à sua publicação em Portugal são bem reveladoras da aura internacional do poeta de Belkiss. Das colunas da Jeune Belgique em que Castro é citado como um poeta destinado a uma "grande notoriété européenne"8, e em que são publicados excertos das suas obras em tradução francesa ${ }^{9}$, às parisienses Revue encyclopédique, La Petite Revue, ou La Revue Française passando pelas consagradas Revue Blanche e Mercure de France o nome e a obra do poeta português não passam desapercebidos.

A obra de Eugénio de Castro teve uma influência considerável no homólogo Modernismo espanhol. Francisco Villaespesa traduziu várias obras do seu congénere português (Salomé y otros poemas (1914) et La sombra del cuadrante (1916) sendo ainda o autor de uma adaptação teatral do rei Galaor em $1912^{10}$. As colectâneas Oaristos e Horas também foram traduzidas por Juan Gonzalez Olmedilla e publicadas em Madrid em $1922^{11}$.

Colocada no contexto do simbolismo europeu e designadamente franco-belga ${ }^{12}$, a poesia dramática compósita de Eugénio de Castro consorcia-se assim no fundo estético e metafísico do simbolismo europeu - fortalecido pela diversidade cultural e pela mobilidade literária de uma plêiade internacional de escritores e de artistas de apetência cosmopolita mas não deixa de irradiar um substrato autóctone a que foram sensíveis os seus críticos e

\footnotetext{
${ }^{7} \mathrm{O}$ acervo epistolográfico de Eugénio de Castro contém precioso material que permite seguir os itinerários europeus do poeta coimbrão. A correspondência do poeta inclui centenas de cartas trocadas com vários nomes de relevo da vanguarda simbolista europeia, entre os quais 0 italiano Vittorio Pica, o inglês Stuart Merril, o alemão Hedwig Barsch, o belga Albert Mockel e o francês Stéphane Mallarmé. A mesma dinâmica cosmopolita se reflecte enquanto docente e director da Faculdade de Letras da Universidade de Coimbra, pelos laços criados com universidades francesas (nomeadamente a Universidade de Estrasburgo, que Ihe atribuiu o grau de doutor honoris causa em 1919) e suíça (Universidade de Genebra) e ainda pela criação de várias "Salas" na Faculdade de Letras, que darão lugar aos Institutos, entre outros o "Instituto de Estudos Franceses" que Eugénio de Castro dirigiu a partir de 1929 juntamente com a Sala Italiana (Ver Laurel, 2001).

${ }^{8}$ La Jeune Belgique, XIV, 1895 : 295.

9 De Oaristos, logo nos números VII-IX de 1891, mas também de Sagramor traduzidos por Philéas Lebesgue e Pilate de Brinn' Gaubast no número XIV de 1895 bem como o poema "Presságios" de Interlúnio, também sob forma de tradução.

${ }^{10}$ Com o título El Rey Galaor. Tragedia en actos y en verso inspirada en un poema de Eugenio de Castro (Castro, 1918).

${ }^{11}$ Sobre a correspondência de Eugénio de Castro com os mentores da literatura hispânica contemporânea (Miguel de Unamuno, Rubén Darío, Eugenio d'Ors, Francisco Villaspesa...) ver Eloísa Alvarez e Antonio Sáez (2007).

${ }^{12}$ Ver designadamente "'Que os olhos livres fazem a alma escrava': a poesia dramática de Eugénio de Castro. Um diálogo interior com o teatro de Maurice Maeterlinck», Actas do VI Congresso Nacional de Literatura Comparada, $X$ Colóquio de Outono Comemorativo das Vanguardas - Universidade do Minho 2009/2010, pp. 1-34 e «Estátua muda, eco branco...': Eugénio de Castro, un poète tragique à la charnière de la modernité", in O Trágico, org. Marta Teixeira Anacleto \& Fernando Matos Oliveira. Coimbra: Imprensa de Coimbra, pp. 47-74.
} 
tradutores estrangeiros. O traço português é marcante na poética do autor, como o indiciam quer a opção por formas tradicionais oriundas dos Cancioneiros, com uso recorrente do verso redondilha maior, quer a escolha de temas, motivos ou figuras lendárias do imaginário luso, fomentando analogias e nelas concentrando aspectos de individuação artística historicizada - de que é exemplar Constança.

Apesar da sua relação matricial com o Simbolismo dentro do qual iniciou a sua produção literária e a partir do qual evoluiu, há deste modo na estética da Eugénio de Castro um carácter marcadamente individual, intrinsecamente ligado à sua cultura e é entre estes dois pólos que constrói um percurso novo e uma singularidade na história da literatura portuguesa. Capere, non capi: assim o sintetizam estas palavras de Hubert Gilot, escrevendo em 1922:

Ami de Moréas, familier de Mallarmé, il a pris part à nos luttes littéraires. En 1896, présidant un banquet en son honneur, Catulle Mendès pouvait dire de lui qu'il était un poète authentique /.../ donna/nt/ l'exemple de ce Symbolisme dont il n'a jamais cessé de pratiquer les tendances essentielles en tout ce qu'elles ont de viable et compatible avec le génie de sa race et de son pays ${ }^{13}$.

Mesmo quando, a partir das Poesias Escolhidas de 1902, se afasta das tensões da modernidade estética, fá-lo através de novo procedimento irónico de capere, non capi: sintoniza as manifestações europeias da crise des valeurs symbolistes (como diria M. Décaudin) e a emergência do Neo-Romantismo como nova hegemonia estilísticoperiodológica, mas submete a tais traços idiolectais as afinidades com a corrente lusitanista desse Neo-Romantismo que induz a crítica e a história literárias a lerem como «neoclássica» essa fase tradicionalista da sua obra.

\footnotetext{
${ }^{13}$ Carta de 10 de Junho de 1922.
} 


\section{Bibliografia}

Alvarez, Eloísa e SÁez Delgado, António (2007). Eugénio de Castro y la Cultura Hispánica. Epistolário, Mérida: ERE.

CABRAL, Maria de Jesus $\left(2010^{\mathrm{a}}\right)$. "Mallarmé: un (dé)placement avantageux dans la sphère symboliste", Nineteenth-Century French Studies, University of Nebraska, Lincoln, 2010, oㅜ 38, 3-4, Spring-Summer, pp. 228-251.

$\left(2010^{b}\right)$. “ «Uma grande sombra que sente e se não vê»: Belkiss nos trilhos da Literatura dramática simbolista", Máthesis, Revista da Faculdade de Letras da Universidade Católica Portuguesa, № 19. Viseu, pp. 77-95.

CASTRO, Eugénio de, Obras poéticas, Lúmen: Lisboa,

Vol. I: Oaristos - Horas - Silva, 1927.

Vol II: Interlúnio - Belkiss - Tiresias, 1927.

Vol III: Sagramor, 1928.

Vol. IV: Salomé - Nereide de Harlem - O rei Galaor - Saudades do Céu, 1929.

(1915). El Rey Galaor. Tragedia en tres actos y en verso inspirada en un poema de Eugenio de Castro, trad. Francisco de Villaespesa, Madrid: Sociedad de Autores Españoles.

(1892). «Poetas Novos », in Jornal do Comércio, no 11561 de 19 de Junho de 1892.

(1893). «Opiniões : o Theatro Moderno », in Diário Popular, no 9441, 18 de Agosto de 1893.

DARío, Ruben (1942). Los raros. Santiago de Chile: Ediciones Ercilla.

D'HeuR, Jean-Marie (1999). “Ars longa Arte breve”. In: D'HeuR, Jean-Marie e PoupART, René (eds.), Centenário da Publicação de Oaristos de Eugénio de Castro - Actas do Colóquio (7- 9 Novembro de 1990) nas Universidades de Liège e Mons, Arquivos do Centro Cultural Calouste Gulbenkian. Lisboa - Paris, pp. 607-629.

DUFAUD, Marc (2008). Dictionnaire fin de siècle. Zutistes, jemenfoutistes, tout l'univers des dandys decadentes. Paris: Scali.

LAUREL, Maria Hermínia Amado (2001). "Eugénio de Castro: dos caminhos da velha Alta coimbrã à consagração europeia", Actas do I Colóquio APHELLE, Associação Portuguesa para a História do Ensino das Línguas e Literaturas Estrangeiras, pp. 243-270.

Lebesgue, Philéas (2007). Portugal no Mercure de France, trad. e coord. de Madalena C. Cruz e Liberto Cruz. Lisboa: Roma edit.

MARnoto, Rita (2009). "Eugénio de Castro entre Simbolismo e Futurismo", In Biblos, no VI, pp. 349-362.

Maeterlinck, Maurice (1999). CEuvres I, Le réveil de L'âme, Poésie et Essais, ed. Paul Gorceix, Bruxelas: Complexe. 
MALLARME, Stéphane (2003). CEuvres complètes, II, ed. Bertrand Marchal. Paris: Gallimard, "Bibl. de la Pléiade".

(1973).Correspondance, IV, Éd. Henri Mondor et Lloyd James Austin. Paris:

Gallimard.

MichaUd, Guy (1995). Le Symbolisme tel qu'en lui-même. Paris: Nizet.

PereIRA, José Carlos Seabra (1975). Decadentismo e Simbolismo na Poesia Portuguesa. Coimbra: Centro de Estudos Românicos.

(1995). História Crítica da Literatura Portuguesa, vol VII, Do fim do século ao Modernismo [ coord. de Carlos Reis]. Lisboa: Editorial Verbo.

(1999). "Eugénio de Castro e a Instituição literária". In: D'HEUR, Jean-Marie e Poupart, René (eds.), Centenário da Publicação de Oaristos de Eugénio de Castro, Actas do colóquio de 7 a 9 de Novembro de 1990, Universidade de Liège et de Mons. Paris: Arquivos do Centro Cultural Gulbenkian,vol. XXVIII, pp. 519-526. 
